\title{
Bibliotecas para a promoção de autonomia em negócios, inovação e tecnologia
}

\author{
Priscila Machado Borges Sena ${ }^{1}$, Jéssica Bedin², Ursula Blattmann ${ }^{3}$, José Antonio Moreiro \\ González ${ }^{4}$ \\ ${ }^{1}$ ORCID: 0000-0002-5612-4315. Programa de Pós-Graduação em Ciência da Informação da \\ Universidade Federal de Santa Catarina, Florianópolis, Santa Catarina. \\ priscilasena.ufsc@gmail.com. \\ ${ }^{2}$ ORCID: 0000-0003-2324-4246. Programa de Pós-Graduação em Ciência da Informação da \\ Universidade Federal de Santa Catarina, Florianópolis, Santa Catarina. Universidade Comunitária \\ da Região de Chapecó - Unochapecó. jessicabedin@unochapeco.edu.br. \\ ${ }^{3}$ ORCID: 0000-0002-8834-0987. Programa de Pós-Graduação em Ciência da Informação da \\ Universidade Federal de Santa Catarina, Florianópolis, Santa Catarina. ursula.blattmann@ufsc.br. \\ ${ }^{4}$ ORCID: 0000-0002-8827-158X. Universidad Carlos III de Madrid, Getafe, Madrid. \\ jamore@bib.uc3m.es.
}

Tipo de contribuição: Comunicação oral

Palavras-chave: Bibliotecas; Autonomia; Negócios; Inovação; Tecnologia.

\section{Introdução}

Pesquisas sobre os impactos dos avanços tecnológicos em comunicação e informação têm aumentado exponencialmente em todo o mundo. Mas além de tratarem sobre formas de como dinamizar a inovação, têm trazido também a preocupação com a desigualdade social, e consequentemente sobre o papel das instituições educacionais e culturais para o fomento igualitário do acesso e uso da informação.

No Brasil, o maior evento profissional e científico da área de Biblioteconomia, o Congresso Brasileiro de Biblioteconomia, Documentação e Ciência da Informação (CBBD), em 2017 teve no primeiro eixo temático a abordagem dos Objetivos do Desenvolvimento Sustentável (ODS), em que trouxe a relação entre os objetivos e o papel das bibliotecas no processo de concretização destes. De acordo com a International Federation of Library Associations and Institutions (IFLA, 2016), por meio do desenvolvimento das bibliotecas é possível ajudar as pessoas a obter informações necessárias para o acesso a oportunidades econômicas, igualdade de gênero, educação de qualidade, e para melhorar sua saúde ou desenvolver suas comunidades.

Diante do exposto e do tema do IX Encuentro de la Asociación de Educación e Investigación en Ciencia de la Información de Iberoamérica y el Caribe, "Datos abiertos e inclusión digital en la era del Big Data", objetiva-se com este trabalho investigar as ações que são e podem ser desenvolvidas em bibliotecas para a promoção de autonomia em negócios, inovação e tecnologia. Objetivo que corresponde a linha temática "4 Los profesionales de la información y documentación frente a los Objetivos de Desarrollo Sostenible de la Agenda 2030 de Naciones Unidas", por meio de emprego descente e crescimento econômico.

Além disso, esta investigação trata-se do desenvolvimento de estudos já realizados sobre "Ecossistema de Startups em Florianópolis: possibilidades para profissionais da Biblioteconomia", em que Sena, Blattmann e Teixeira (2017) indicaram possibilidades de atuação para profissionais da Biblioteconomia a partir da relação entre as características de um ecossistema de startups e as competências para profissionais da informação da Special Libraries Association (SLA, 2016); e 
"Informação para autonomia em negócios, inovação e tecnologia", onde Sena, Amorim e Blattmann (no prelo) identificaram as demandas informacionais a serem atendidas a fim de contribuir para a autonomia em aglomerados denominados como ecossistemas.

De acordo com a IFLA (2016), as bibliotecas apoiam o objetivo 4 no que concerne a provisão de acesso à informação e capacitação para desenvolver habilidades que as pessoas necessitem para encontrar melhores postos de trabalhos, candidatar-se a eles e ter sucesso nesses empregos. Desta forma, propõe-se relacionar as indicações de ambos estudos por intermédio de uma pesquisa qualitativa e descritiva para o alcance do objetivo proposto.

\section{Inclusão a partir das Bibliotecas}

Os contextos de negócios, inovação e tecnologia têm o conhecimento como recurso chave para os seus desenvolvimentos, assim segundo Ganguli (2007), as bibliotecas e profissionais da informação têm o papel de organização e disseminação do conhecimento para benefício local e global. Calzada e Marzal (2013) corroboram ao considerarem válida diante das preocupações sociais, a conexão dos profissionais da informação ao desenvolvimento socioeconômico não apenas como provedores de acesso, mas principalmente como mediadores nos processos de criação e inovação de conhecimento.

Exemplo de atividade possível de ser realizada foi abordado por Annet Kinengyere (2007), ao apresentar as bibliotecas em universidades e instituições de pesquisa em Uganda que ofereciam uma gama de oportunidades para funcionários e estudantes, por meio do desenvolvimento de programas para sessões de habilidades informacionais com base em suas necessidades individuais. Dessa forma, as bibliotecas universitárias podem prover de habilidades baseadas na transferência de gerenciamento de tecnologia e não apenas associadas a classes e empréstimos de livros (Kavoura \& Anderson, 2016).

Porém, faz-se necessária a compreensão dos desafios que os contextos de negócios, inovação e tecnologia trazem para as bibliotecas. Allen e Taylor (2017) elucidam que entender o impacto do uso das inovações tecnológicas em bibliotecas acadêmicas fornece orientação para a implementação de métodos inovadores para ajudar os profissionais da Ciência da Informação aspirantes a auxiliar o ensino e a aprendizagem dos usuários. Uma vez que, o papel das bibliotecas acadêmicas foi modificado de um depósito de recursos para um local de aprendizado, educação, pesquisa e inovações (Khan \& Bhatti, 2017).

Esse novo local incorpora, por exemplo, a lógica dos espaços criativos que não estão diretamente relacionados a nenhuma ferramenta ou organização específica, organização patrocinada ou publicação (Hussain \& Nisha, 2017). Conforme os autores, os chamados makerspaces adotam qualquer espaço que torne a aprendizagem inovadora igualmente desprovida de ferramentas / equipamentos e espaço alocado. Destacaram que a democratização da tecnologia, a manutenção da percepção da biblioteca como líder em inovação tecnológica e a necessidade de apoio acadêmico são as razões mais citadas para se incluir um makerspace em uma biblioteca acadêmica.

Santos Neto e Zaninelli (2017), vislumbraram a implantação de makerspaces em bibliotecas escolares, como uma possibilidade para que a inovação se concretize. Concluíram que o desafio dessa implantação se encontra na internalização da cultura maker para as bibliotecas e bibliotecários, pois inova a concepção existente em relação aos seus produtos e serviços. De certo modo esse desafio já havia sido abordado por Stephens (2011), quando apresentou que a biblioteca do século 21 deveria ter um ambiente de laboratório com um elemento de mutabilidade e energia da inovação.

Verifica-se que o desafio para os bibliotecários em todos os tipos de bibliotecas pode estar, de acordo com Malafi, Liu e Goldstein (2017), em como apoiar uns aos outros por meio do compartilhamento de materiais e abordagens. E ainda, em como compartilhar boas práticas para o 
desenvolvimento de produtos e serviços que corroborem com ambientes em que empreender, inovar, utilizar e propor uma tecnologia são ações essenciais.

Esses ambientes têm desafios que vão desde a competência crítica em informação, literacia da informação digital, a alfabetização de direitos autorais, uma vez que tratam-se de contextos de germinação constante da criatividade por meio de ideias e projetos. Posto isso, as bibliotecas e outras instituições de ensino e cultura podem desempenhar papeis protuberantes na promoção de autonomia em negócios, inovação e tecnologia, por intermédio de ações que preparem seus frequentadores.

\section{Ações para a autonomia em negócios, inovação e tecnologia}

Para indicar possibilidades para profissionais da Biblioteconomia em Ecossistema de Startups, Sena, Blattmann e Teixeira (2017, p. 2474), primeiro definiram o que seria um Ecossistema de Startups, "um ambiente favorável a interação mútua entre distintos atores, com vistas ao desenvolvimento de startups", e posteriormente relacionaram essa definição com as competências para profissionais da informação da Special Libraries Association (SLA, 2016). Identificaram como possibilidades de atuação a gestão da documentação, gestão da informação, análise de informação, gestão do conhecimento, curadoria, consultoria no que concerne a elaboração de projetos, mapeamento de fontes de informação pertinentes, disseminação seletiva da informação, entre outras e, destacaram por último a inserção como empreendedor de inovações tecnologias. Concluíram que a inovação apresenta distantes nuances devido aos diferentes ambientes de informação. Sendo a criatividade o combustível para o aproveitamento de oportunidades e desenvolvimento em produtos, serviços, tarefas e atividades.

Sena, Amorim e Blattmann (no prelo) identificaram as demandas informacionais de aglomerados denominados como ecossistemas, a partir da apresentação das definições de ecossistemas de negócios, empreendedorismo, inovação e startups. Depois relacionaram com os atributos-chave para abordagem ecológica da informação de Davenport e Prusak (1998). Então chegaram as demandas informacionais de: mapeamento de fontes de informação pertinentes; identificação de ferramentas e mecanismos de integração dos diversos tipos de informação; busca elou projeto de sistemas de informação interativos; identificação de momentos chave nos processos existentes; representação e descrição da informação e do conhecimento; caracterização do comportamento pessoal e informacional. Por fim, elucidaram a importância da promoção de capacitação para acesso e uso autônomos.

Diante dos resultados de ambos os estudos, e das referências utilizadas como suporte para este trabalho, espera-se que algumas ações que podem ser desenvolvidas em bibliotecas, sejam elas escolares, comunitárias, públicas e universitárias, tenham consequência direta para a promoção de autonomia em ambientes que envolvam negócios, inovação e tecnologia. Na sequência são elencadas ações com respectivos exemplos no Brasil.

1 Direcionamento de espaços para coworking, que segundo Bouncken e Reuschl (2018), referem-se à ideia de uma economia de partilha em duas dimensões que permitem o acesso a ativos físicos compartilhados (infraestrutura, cafeteria etc.) e o compartilhamento de ativos intangíveis (informação, conhecimento etc.).

- Biblioteca Parque Villa-Lobos;

- Biblioteca do Memorial da América Latina.

2 implantação de makerspace, que de acordo Hussain e Nisha (2017) proporciona uma aprendizagem inovadora; 
- A ONG Recode ${ }^{1}$ tem como objetivo transformar 50 bibliotecas públicas em makerspaces, com vistas a inclusão digital.

3 cursos, oficinas e workshops;

- sobre a importância de uma pesquisa no dia a dia e não somente na escola ou universidade;

- sobre a importância e como checar uma fonte de informação (diferenciar as Fake News);

- sobre a alfabetização de direitos autorais.

4 programas de desenvolvimento de Competência em Informação;

- A rede de Bibliotecas Parque ${ }^{2}$ do Estado do Rio de Janeiro apresenta programações que promovem de maneira criativa a competência em informação.

5 programas de desenvolvimento de Literacia em Informação Digital.

- A biblioteca universitária da Universidade Federal de Santa Catarina oferece por exemplo, duas capacitações específicas em nível básico e avançado sobre as Fontes de informação on line.

Ressalva-se que essas ações só refletirão nos ambientes de negócios, inovação e tecnologia a partir da integração das bibliotecas na comunidade local, tornando-a parte de suas ações.

\section{Considerações}

Com o objetivo de investigar as ações que poderiam ser desenvolvidas em bibliotecas para a promoção de autonomia em negócios, inovação e tecnologia, este trabalho foi elaborado, tendo obtido êxito ao elencar cinco ações concernentes das demandas informacionais emergentes destes segmentos e as possibilidades de atividades que neles refletem. Deste modo, reforça-se a importância que as bibliotecas podem ter em suas comunidades quando alinhadas com suas necessidades econômicas e sociais.

\section{Agradecimentos}

À Coordenação de Aperfeiçoamento de Pessoal de Nível Superior (CAPES) do Brasil por financiar a bolsa de estudos do doutorado em andamento.

\section{Referências}

Allen, L. E., \& Taylor, D Deborah M. (2017). The role of the academic Library Information Specialist (LIS) in teaching and learning in the 21 st century. Information Discovery and Delivery, 45(1), 1-9. Recuperado em 5 janeiro, 2019, de https://www.emeraldinsight.com/doi/full/10.1108/IDD-09-2016-0030

Annet Kinengyere, A. (2007). The effect of information literacy on the utilization of electronic information resources in selected academic and research institutions in Uganda. The Electronic

\footnotetext{
${ }^{1}$ Disponível em: https://recode.org.br/quem-somos/.

${ }^{2}$ Disponível em: http://www.bibliotecasparque.rj.gov.br/bibliotecas/conceito-parque/
} 
Library, 25(3), 328-341. Recuperado em 5 janeiro, 2019, de

https://www.emeraldinsight.com/doi/full/10.1108/02640470710754832

Bouncken, R. B., \& Reuschl, A. J. (2018). Coworking-spaces: how a phenomenon of the sharing economy builds a novel trend for the workplace and for entrepreneurship. Review of Managerial Science, 12(1), 317-334.

Davenport, T. H. (1998). Ecologia da informação: por que só a tecnologia não basta para o sucesso na era da informação. São Paulo: Futura.

Ganguli, S. (2007). Changing paradigm for information professionals in knowledge management age. DESIDOC Journal of Library \& Information Technology, 27(5), 5-16. Recuperado em 5 janeiro, 2019, de http://122.252.233.35/ojs/index.php/djlit/article/view/135 https://www.emeraldinsight.com/doi/abs/10.1108/LR-06-2015-0062

Hussain, A., \& Nisha, F. (2017). Awareness and Use of Library Makerspaces among Library Professionals in India: A Study. DESIDOC Journal of Library \& Information Technology, 37(2). Recuperado em 5 janeiro, 2019, de https://pdfs.semanticscholar.org/a537/b3dfa1ac2b7aa50f7a123f4c24afae7e84fe.pdf

International Federation of Library Associations and Institutions (IFLA) (2016). Access and Opportunity for all: How Libraries Contribute to the United Nations 2030 Agenda. The Hague, Netherlands: IFLA. Recuperado em 5 janeiro, 2019, de http://www.ifla.org/files/assets/hq/topics/libraries-development/documents/access-and-opportunityfor-all.pdf

Kavoura, A., \& Andersson, T. (2016). Applying Delphi method for strategic design of social entrepreneurship. Library Review, 65(3), 185-205. Recuperado em 5 janeiro, 2019, de

Khan, S. A., \& Bhatti, R. (2017). Digital competencies for developing and managing digital libraries: An investigation from university librarians in Pakistan. The Electronic Library, 35(3), 573-597. Recuperado em 5 janeiro, 2019, de https://www.emeraldinsight.com/doi/abs/10.1108/EL06-2016-0133

Malafi, E., Liu, G., \& Goldstein, S. (2017). Information Literacy: Business and Workplace Information Literacy: Three Perspectives. Reference \& User Services Quarterly, 57(2), 79-85. Recuperado em 5 janeiro, 2019, de https://journals.ala.org/index.php/rusq/article/view/6521

Prado, J. C., \& Marzal, M. A. (2013). Library and Information Professionals as Knowledge Engagement Specialists. Theories, Competencies and Current Educational Possibilities in Accredited Graduate Programmes. Information Research: an international electronic journal, 18(3), n3. Recuperado em 5 janeiro, 2019, de https://eric.ed.gov/?id=EJ1044648

Santos Neto, J. A., \& Zaninelli, T. B. (2017). Biblioteca escolar com makerspace: um estudo de caso na Biblioteca Abraham Lincoln. RBBD. Revista Brasileira de Biblioteconomia e Documentação, 13, 2633-2656. Recuperado em 5 janeiro, 2019, de https://rbbd.febab.org.br/rbbd/article/view/1005 
Sena, P., Blattmann, U., \& Teixeira, C. (2017). Ecossistema de Startups em Florianópolis: possibilidades para profissionais da Biblioteconomia. RBBD. Revista Brasileira de Biblioteconomia e Documentação, 13, 2571-2588. Recuperado em 5 janeiro, 2019, de https://rbbd.febab.org.br/rbbd/article/view/864/957

Sena, P.M.B., Amorim, I. S., \& Blattmann, U. (no prelo). Informação para autonomia em negócios, inovação e tecnologia. Brajis - Brazilian Journal of Information Science: Research Trends.

Special Libraries Association (SLA) (2016). Competencies for Information Professionals. Recuperado em 10 julho, 2017, de https:/www.sla.org/about-sla/competencies/

Stephens, W. S. (2011). The school librarian as leader: out of the middle, into the foreground. Knowledge Quest, 39(5), 18. Recuperado em 5 janeiro, 2019, de https://search.proquest.com/docview/869882836/abstract/E9CAB318E0FB456EPQ/1?accountid=1 4501 